\title{
Combined Effect of Pressure and Temperature on the Viscous Behaviour of All-Oil Drilling Fluids
}

\author{
J. Hermoso, F. Martínez-Boza* and C. Gallegos \\ Departamento de Ingeniería Química, Universidad de Huelva, Facultad de Ciencias Experimentales, Campus del Carmen, 21071 Huelva - Spain \\ e-mail: martinez@uhu.es \\ * Corresponding author
}

\begin{abstract}
The overall objective of this research was to study the combined influence of pressure and temperature on the complex viscous behaviour of two oil-based drilling fluids. The oil-based fluids were formulated by dispersing selected organobentonites in mineral oil, using a high-shear mixer, at room temperature. Drilling fluid viscous flow characterization was performed with a controlled-stress rheometer, using both conventional coaxial cylinder and non-conventional geometries for High Pressure/High Temperature (HPHT) measurements. The rheological data obtained confirm that a helical ribbon geometry is a very useful tool to characterise the complex viscous flow behaviour of these fluids under extreme conditions.

The different viscous flow behaviours encountered for both all-oil drilling fluids, as a function of temperature, are related to changes in polymer-oil pair solvency and oil viscosity. Hence, the resulting structures have been principally attributed to changes in the effective volume fraction of disperse phase due to thermally induced processes. Bingham's and Herschel-Bulkley's models describe the rheological properties of these drilling fluids, at different pressures and temperatures, fairly well. It was found that Herschel-Bulkley's model fits much better B34-based oil drilling fluid viscous flow behaviour under HPHT conditions.

Yield stress values increase linearly with pressure in the range of temperature studied. The pressure influence on yielding behaviour has been associated with the compression effect of different resulting organoclay microstructures. A factorial WLF-Barus model fitted the combined effect of temperature and pressure on the plastic viscosity of both drilling fluids fairly well, being this effect mainly influenced by the piezo-viscous properties of the continuous phase.
\end{abstract}

Résumé - Effet combiné de la pression et de la température sur le comportement visqueux des boues de forage non-aqueuses — L'objectif principal de cette recherche était d'étudier l'influence combinée de la pression et de la température sur le comportement visqueux de deux boues de forage à base d'huile.

Les boues de forage à base d'huile ont été formulées par dispersion d'organo-bentonites dans de l'huile minérale à température ambiante, en utilisant un mélangeur à fort cisaillement. La caractérisation de l'écoulement visqueux des boues de forage a été réalisée avec un rhéomètre à contrainte imposée, utilisant un cylindre coaxial conventionnel et les géométries non conventionnelles pour des mesures à Hautes Pressions/Hautes Températures (HPHT). Les données rhéologiques obtenues confirment que la géométrie en " ruban hélicoïdal » est un outil très utile pour la caractérisation du comportement de l'écoulement des fluides complexes dans des conditions extrêmes. 
Les différents comportements visqueux rencontrés pour les deux types de boues à base d'huile, en fonction de la température, sont liés aux changements de solvabilité du couple polymère-huile et de la viscosité de l'huile. Par conséquent, les structures qui en résultent sont principalement dues aux changements de la fraction volumique effective de la phase dispersée due à des procédés induits thermiquement.

Les modèles de Bingham et Herschel-Bulkley décrivent avec précision les propriétés rhéologiques de ces fluides de forage, à différentes pressions et températures. Le modèle de Herschel-Bulkley s'adapte mieux au comportement d'écoulement de la boue de forage B34 dans les conditions HPHT.

Les valeurs de contraintes seuil augmentent linéairement avec la pression dans le domaine de température étudiées. L'influence de la pression sur le rendement a été associée à l'effet de compression des différentes microstructures d'organo-argiles qui en résultent. Le modèle factoriel WLF-Barus s'ajuste bien à l'effet combiné de la température et de la pression sur la viscosité plastique des deux fluides de forage. Cet effet est principalement influencé par les propriétés piezo-visqueuses de la phase continue.

\section{SYMBOLS}

$c_{1} \quad$ Experimental constant

$c_{2} \quad$ Experimental constant, $T,\left({ }^{\circ} \mathrm{C}\right)$

HPHT High Pressure/High Temperature

$K \quad$ Consistency index

$n \quad$ Flow index

$p \quad$ Pressure

$p_{0} \quad$ Pressure of reference

$T \quad$ Temperature

$T_{0} \quad$ Temperature of reference

$\beta \quad$ Piezo-viscous coefficient

$\beta_{0} \quad$ Empirical parameter

$\beta_{1} \quad$ Empirical parameter

$\beta_{\tau} \quad$ Piezo-yield stress coefficient

$\Delta p \quad$ Differential pressure

$\dot{\gamma} \quad$ Shear rate

$\eta \quad$ Viscosity

$\eta_{0} \quad$ Viscosity or plastic viscosity at 1 bar and $40^{\circ} \mathrm{C}$

$\eta_{p} \quad$ Plastic viscosity

$\tau \quad$ Shear stress

$\tau_{c} \quad$ Yield stress

$\tau_{B} \quad$ Bingham's yield stress

$\tau_{H} \quad$ Herschel-Bulkley's yield stress

$\tau_{c 0} \quad$ Bingham's or Herchel-Bulkley's yield stress, at 1 bar and $40^{\circ} \mathrm{C}$

$\chi \quad$ Flory-Huggins interaction parameter for the polymer-solvent pair

\section{INTRODUCTION}

The oil industry is increasingly drilling more technically challenging and difficult wells. Drilling of deeper wells worldwide requires a constant searching for adequate drilling muds to overcome extreme conditions (Williams et al., 2011). The successful completion of an oil well and its cost depend, on a considerable extent, on the properties of drilling fluids. Hence, the proper selection of the drilling fluid during rotatory drilling process is essential for dealing with the wide range of challenges encountered, particularly in high angle drilling, completion and workover operations.

Most of the worldwide drilling operations use waterbased muds because of their lower environmental impact and cheaper cost (Caenn and Chillingar, 1996). However, water muds also can give wellbore instability problems, such as bit balling, wash out, high torque and drag, due to clay swelling at extreme temperature conditions. On the contrary, non aqueous drilling fluids (oil based and synthetic based), owing to their excellent lubricity, high rate of penetration and outstanding thermal stability, are often used to drill difficult wells, such as long sections of high angle and/or HPHT wells (Ghalambor et al., 2008).

Drilling fluid viscous behaviour is a critical issue in the success of drilling operations, particularly for drill cuttings removal. The properties that drilling fluids should possess are appropriate viscosity, high-shear thinning behaviour and a finite yield stress for suspending and transferring drill cuttings to the surface (Kelessidis et al., 2007). Nevertheless, the rheological characterization of these systems is not a trivial task because of the inherent heterogeneous nature of the system. The use of non-conventional geometries, such as helical ribbons and blade turbines, has become valuable tools for characterizing the viscous flow behaviour of disperse systems, mainly due to the elimination of serious wall slip effects of apparent yield stress materials (Barnes and Nguyen, 2001; O'Shea and Tallon, 2011). Taking into account 
the particular advantages of this mixing-rheology technique, a better rheological characterization of drilling fluids can be achieved, mainly at low shear rates.

In a previous work (Hermoso et al., 2014), the influence of both pressure and organoclay concentration, at a given constant temperature, on the viscous flow behaviour of all-oil drilling fluids, formulated with two organobentonites, using an extended Sisko model, was highlighted. This model fitted the flow behaviour of these suspensions, in the range of intermediate to high shear rates, fairly well. However, Sisko's model is not useful to estimate an apparent yield stress. This is why, in this work, two well-known yield-stress models used in drilling mechanics, Bingham and Herschel-Bulkley models, were tested for describing the viscous flow behaviour of all-oil drilling fluids.

On the other hand, data concerning HPHT influence on the yielding behaviour of oil drilling suspensions are very limited ( $\mathrm{Lu}$ et al., 2008; Zhao et al., 2009). However, knowledge of the flow behaviour of clay-based drilling fluid, as function of temperature and pressure, is decisive in order to deal with different important issues, such as excessive torque, gelation, hole cleaning or barite sag (Shahbazi et al., 2007). In this sense, one of the objectives of this study was to define the temperature-pressure-shear stress relationship for two organoclays suspensions, aiming to support a physical interpretation of the rheological behaviour obtained. In addition, this work also aims to check the accuracy of two rheological models that describe the combined effect of both pressure and temperature on the viscous flow behaviour of theses suspensions. Particular efforts has been dedicated to the yielding transition, measured by using non-conventional geometries (double helical ribbon), aiming to get further insight into the complex rheology of these fluids in extreme HPHT conditions.

\section{MATERIALS AND PROCEDURES}

\subsection{Materials}

The organoclays used in the present study (B34 and B128) were purchased from Elementis (Belgium) and used without further purification. These organoclays are industrial powdered products, typically used in oil well drilling. The original organoclays were modified by a cationic exchange reaction between bentonite clay and different quaternary ammonium chloride ions, dimethyl-dihidrogenated tallow ion for B34 and dimethyl-benzyl-hydrogenated tallow for B128. The particle size distributions of dry powders were measured by light scattering (Mastersizer Scirocco 2000, Malvern Instruments Ltd, UK). Sauter's mean diameters were $9.81 \mu \mathrm{m}$ (B34) and $6.17 \mu \mathrm{m}$ (B128), respectively.

The SR-10 oil was a naphthenic lubricating oil, supplied by Verkol (Spain), with a viscosity of $115 \mathrm{cSt}$ and a specific gravity of $0.916 \mathrm{~g} / \mathrm{cm}^{3}$, at $40^{\circ} \mathrm{C}$.

\subsection{Drilling Fluid Manufacture}

For the preparation of the drilling fluids, $5 \mathrm{wt} \%$ organoclay was mixed with SR-10 base oil, using a high shear mixer (Ultraturrax, Ika, Germany), at $9000 \mathrm{rpm}$, for 5 minutes and room temperature. Before mixing, both organoclays were wetted with oil, for an hour, to guarantee good organoclay dispersion into the oil base. When the dispersion process was finished, the resulting suspensions became viscous and stable. The all-oil drilling fluids formulated were stored at room temperature.

\subsection{Rheological Characterization}

Traditional procedures to characterize drilling mud rheology follow the API recommendations using the FANN rheometer for a field characterization. In this work, in order to get a better accuracy in the low shear-rate region, viscous flow measurements were carried out using a controlled stress rheometer, MARS II, from Thermo Scientific (Germany). Four geometries were used: a conventional coaxial cylinder geometry $(41 \mathrm{~mm}$ inner diameter, $1 \mathrm{~mm}$ gap, $60 \mathrm{~mm}$ length) and a serrated plate-and-plate geometry ( $35 \mathrm{~mm}$ diameter, $1 \mathrm{~mm}$ gap) for atmospheric pressure rheological tests; whilst a coaxial cylinder geometry ( $38 \mathrm{~mm}$ diameter, $80 \mathrm{~mm}$ length) and a double helical ribbon geometry $(36 \mathrm{~mm}$ diameter, $78 \mathrm{~mm}$ length), in a pressure cell D400/200 (Thermo Scientific, Germany), were used for HPHT measurements. The latter sensor, called DHR, has a nonconventional geometry, previously calibrated with a Newtonian fluid and several shear-thinning fluids, in the pressure range used in the present study (Hermoso et al., 2012). The cell D400/200 is a pressure vessel of $39 \mathrm{~mm}$ inner diameter. Inside the cell, the double helical ribbon geometry was put in contact with a sapphire surface, at the bottom of the vessel, by a steel needle. This inner cylinder was equipped, at the top, with a secondary magnetic cylinder (36 mm diameter, $8 \mathrm{~mm}$ length), magnetically coupled to a tool outside the cell, which was connected to the motor-transducer of the rheometer. The pressure cell was connected to a hydraulic pressurization system, which consists of two units, a high pressure valve and a hand pump (Enerpac, USA), connected by a high pressure line. The pressure cell 
was pressurized using, as pressurizing liquid, the same fluid to be tested. A pressure transducer GMH 3110 (Gresingeg Electronic, Germany), able to measure differential pressures ranging from 0 to 400 bar $(0.1$ bar resolution), was used.

Steady-state viscosity measurements, at different differential pressures $(0,100,200,300$ and 390 bar $)$ and temperatures $\left(40,80,100,120\right.$ and $\left.140^{\circ} \mathrm{C}\right)$, were performed in a shear rate range dependent on sample viscosity. Temperature was fixed with a circulating silicone bath (DC30 Thermo Scientific, Germany). In order to guarantee the same conditions of the drilling fluids at the starting point, all samples were pre-sheared at $100 \mathrm{~s}^{-1}$, for $25 \mathrm{~s}$, before the rheological tests. Steadystate viscosities were obtained by performing step increases in shear stress. Each shear stress was applied on the sample during $120 \mathrm{~s}$. After this elapsed time, a constant shear rate was always obtained.

Downward shear rate sweep flow curves were used to compare drilling fluids viscous behaviour. This type of procedure is highly recommend when viscous flow parameters are to be used for the purpose of calculating pressure drop in a condition corresponding to that prevailing at the point of interest in the well (Darley and Gray, 1988). According to this procedure, the yield stresses estimated from both models are defined as dynamic yield stresses.

Before performing the rheological tests, all samples were submitted to storage stability tests. In this sense, closed non-agitated containers were introduced in an oven, at temperatures between $40^{\circ} \mathrm{C}$ and $140^{\circ} \mathrm{C}$. No particle separation was observed after $48 \mathrm{~h}$ ageing.

On the other hand, at least, two replicates of each rheological test were performed on fresh samples. The results shown correspond to the mean values obtained. Standard deviations among replicates were always inferior to $\pm 5 \%$.

\subsection{Yield Stress Models}

The Bingham model is the most traditional model used to fit the viscoplastic behaviour of drilling fluids (Rossi et al., 2002):

$$
\tau=\tau_{B}+\eta_{P} \dot{\gamma}
$$

where $\tau_{B}$ is the apparent Bingham yield stress and $\eta_{p}$ is the plastic viscosity. The yield stress values can be obtained by extrapolating the flow curve to zero shear rate. On the other hand, the plastic viscosity is the slope of the stress-shear rate curves at high shear rates. Most drilling fluids are not exactly described by this model, although drilling fluid behaviour can be predicted reasonably well, for practical purposes (Harris and Osisanya, 2005).
However, the three-parameter Herschel-Bulkley model is in much stronger agreement with drilling fluids experimental rheological data, especially at low shear rate:

$$
\tau=\tau_{H}+K \dot{\gamma}^{n}
$$

where $\tau_{H}$ is the apparent Herschel-Bulkley yield stress, $K$ is the consistency index and $n$ is the flow index. This model accounts for both the yielding behaviour as well as for the further non-linear relationship between shear stress and shear rate of i.e. bentonite suspensions (Kelessidis et al., 2009), and most drilling fluids (Munawar and Jan, 2012a,b). For oil muds, HerschelBulkley's model has been used to describe the influence of both temperature and pressure on the complex flow behaviour at intermediate and high shear rates fairly well (Herzhaft et al., 2003).

All the rheological parameters of these two models were estimated by using a curve-fitting technique with a weighted-average method.

\section{RESULTS AND DISCUSSION}

\subsection{Effect of Temperature at Atmospheric Pressure}

Figure 1 shows a comparison between the flow curves obtained from downward shear rate sweep tests using the serrated plate-plate geometry (PR35) and the Double

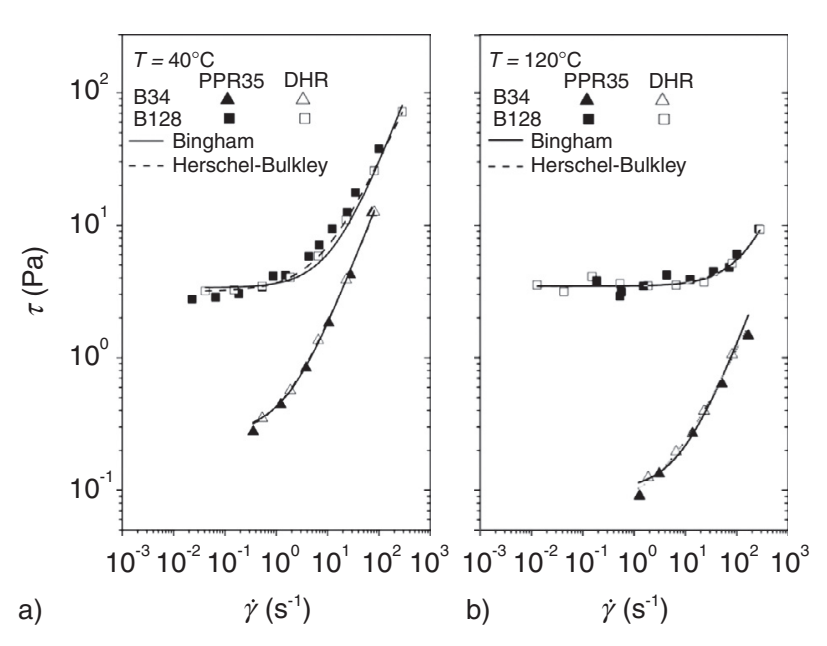

Figure 1

Viscous flow curves, obtained by using serrated plate-plate and double helical ribbon geometries, for both oil-drilling fluids at a) $40^{\circ} \mathrm{C}$ and b) $120^{\circ} \mathrm{C}$. 
Helical Mixer (DHR), for both drilling fluids, at $40^{\circ} \mathrm{C}$ (Fig. 1a) and $120^{\circ} \mathrm{C}$ (Fig. 1b). It can be seen that measurements performed using the non-conventional geometry (DHR) are in good agreement with those obtained using the rough plate-plate geometry. Consequently, in the temperature range tested, both geometries give a reliable measurement of the viscous flow behaviour of these fluids in the low shear rate region. These results confirm that the helical ribbon geometry is an appropriate tool to cover accurately a wide shear rate range, especially for high-viscosity fluids (Hermoso et al., 2012). Likewise, the viscous flow curves correspond to a non-Newtonian flow behaviour over a wide range of shear rate, showing an apparent yield stress, mainly for sample B128. From these results, it can be deduced that surface modification of bentonite particles by different organic groups modifies the flow behaviour of these suspensions (Tropea et al., 2007). In addition, the viscous flow behaviour of both drilling fluids drastically changes as temperature increases. Thus, the drilling fluid B34 exhibits significantly lower shear stresses, in the low shear rate region, as temperature increases. Meanwhile, drilling fluid B128 viscous flow curve exhibits a well-defined yield stress in the low shear rate region at high temperature. This temperature-dependent behaviour was reported by Rossi et al. (1999) for water-based muds. In general, at $40^{\circ} \mathrm{C}$, Herschel-Bulkley's model fits the experimental data better than Bingham's model, particularly for B128-based drilling fluid, whilst, at $120^{\circ} \mathrm{C}$, both models predict the flow behaviour of the two all-oil drilling fluids fairly well, being the deviations between predicted and calculated shear stresses within the order of the experimental error $( \pm 10 \%)$.

Figure 2 depicts upward and downward viscous flow curves for the all-oil drilling fluids studied, at atmospheric pressure and $40^{\circ} \mathrm{C}$. Upward and downward shear sweep tests were performed with the double helical ribbon geometry after suspension manufacture. At this temperature, no hysteresis was observed for B34-based drilling fluid (Fig. 2a). Nevertheless, as can be observed in Figure $2 b$, the shear stress values obtained in the upward shear rate ramp are, in general, slightly higher than those in the downward shear rate ramp for B128based drilling fluid. This behaviour is typical of clay suspensions, such as drilling fluids, as the interparticle network breaks down in separate flocs, which decrease further in size, when shear rate is increased (Abu-Jdayil, 2011). The slightly different hysteresis degrees of this suspension, in the shear rate range studied, could be explained on the basis of a competition between breakup and recombination of structural elements (flocs). Besides, it should be mentioned that these systems do not display significant thixotropic effects,

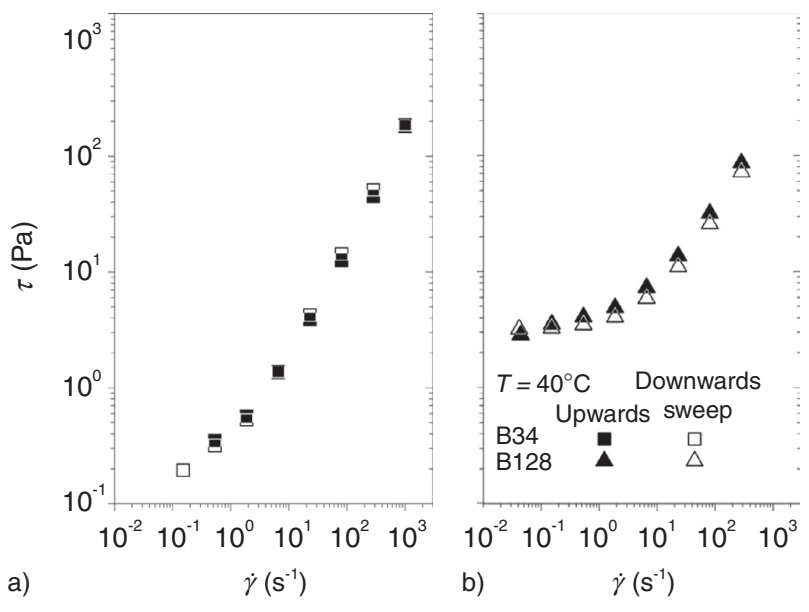

Figure 2

Upward and downward viscous flow curves for B34-based a) and B128-based b) drilling fluids at $40^{\circ} \mathrm{C}$.

at temperatures above $40^{\circ} \mathrm{C}$, under these experimental conditions. On the other hand, both organoclay suspensions exhibit a shear-thinning behaviour, due to the alignment of basal faces of particles in the direction parallel to the applied shear (Massinga et al., 2010). Additionally, the B128-based suspension presents higher yielding point than B34-based suspensions, indicating that the structure of the former is more resistant to large rearrangements responsible for the yielding behaviour and the destruction of such microstructure (Møller et al., 2006). This behaviour, precisely a high apparent yield stress and weak thixotropy, seems to be related to strongly connected clay aggregates, due to a high degree of swelling, developed by interactions between the benzyl nature of the covered surface B128 clays and the naphthenic oil (Burgentzlé et al., 2004). Conversely, the resulting structures, for B34-based drilling fluid, showing relatively low yield stress values, suggest less connected formations, which are easier to orient in the flow field.

Figure 3a displays the evolution of the apparent yield stress with temperature for the drilling fluids studied, at atmospheric pressure, obtained from Bingham's model fitting. As can be observed, the yield stress values, and their evolution with temperature, are different depending on the sample studied. Thus, for B34-based drilling fluid, the yield stresses in the temperature range studied show similar values for $40^{\circ} \mathrm{C}$ and $140^{\circ} \mathrm{C}$, with a minimum value at $80^{\circ} \mathrm{C}$. Otherwise, the yield stress values encountered for B128-based suspension are almost constant up to $120^{\circ} \mathrm{C}$, showing a noticeable increase at 


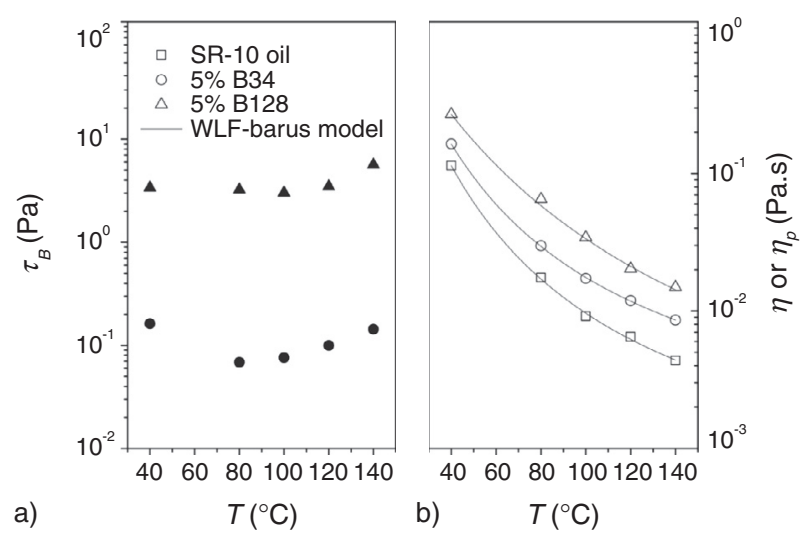

Figure 3

Temperature dependence of Bingham's yield stress a) and viscosity (SR-10)/plastic viscosity b) for both drilling fluids.

higher temperature. In addition, significantly higher yield stress values for B128 samples (at least one order of magnitude) are observed.

The precise physical origin of the influence of temperature on drilling fluid yield stress is not clear. A possible explanation for the different behaviour of the oil drilling fluids studied may be related to changes in polymer-oil pair solvency with temperature. Thus, in the case of polymer-covered particles, the type of interaction is governed by the Flory-Huggins interaction parameter, $\chi$ if $\chi<0.5$ (good solvents), the interaction is repulsive, and, if $\chi>0.5$ (bad solvents), the interaction is attractive (Quemada and Berli, 2002). The low yield stress values for B34-based drilling fluid suggest a short-range attractive force between the particles, which develop a network of aggregates weakly interconnected (Moraru, 2001).

On the other hand, it is worth noting that the unusual temperature dependence for B128-based suspension suggests a thermal thickening above a threshold temperature $\left(T>120^{\circ} \mathrm{C}\right)$. The possible thermo-thickening phenomenon of organoclay suspensions in oil is still unclear. Apparently, the rise in temperature probably leads to stronger repulsive interactions between flocs, due to the improvement in the solvency between the aromatic group of the clay and the naphthenic oil. Then, above the threshold temperature, particle associations might undergo an increase in the effective volume. Thus, an increase in volume fraction leads to an increase in yield stress value, as has been observed by other authors for clay suspensions (Minase et al., 2008). Interestingly, this particular behaviour has been recently reported by
Wu et al. (2012), who also suggested an increase in the effective volume fraction with increasing temperature for particulate dispersion in non-aqueous media.

Figure $3 \mathrm{~b}$ shows the evolution of plastic viscosity with temperature for the drilling fluids studied, at atmospheric pressure. The Newtonian viscosities for the base oil (SR-10) have been also included as reference. A factorial WLF-Barus model fits the above-mentioned dependence fairly well (average error less than 10\%).

As expected, drilling fluid plastic viscosity always decreases with temperature (Joshi and Pegg, 2007), being its dependence very similar to that of the base oil. These results suggest that the viscous flow behaviour of these fluids is largely governed by the viscosity of the base oil, as has been reported elsewhere (Herzhaft et al., 2001). Nevertheless, drilling fluids show significantly higher viscosities than the naphthenic oil media, in the whole range of temperature tested, as shown in Figure $3 \mathrm{~b}$. In addition, the different plastic viscosities obtained for both all-oil drilling fluids, formulated with the same thickener concentration, suggest the development of different microstructures, being the strength of the covered particle-particle interactions stronger for B128-based fluid.

\subsection{Influence of Temperature and Pressure on Flow Behaviour of All-Oil Drilling Fluids}

Figure 4 displays the viscous flow curves (shear stress versus shear rate and viscosity versus shear rate) for B128-based oil drilling fluid, as a function of pressure, at $40^{\circ} \mathrm{C}$ (Fig. $\left.4 a, c\right)$ and at $140^{\circ} \mathrm{C}$ (Fig. $4 b, d$ ), obtained by using the non-conventional geometry. As can be observed, the yield stress increases with temperature in the pressure range studied. On the other hand, the critical shear rate for the onset of the liquid-like regime also increases with temperature $\left(\dot{\gamma} \sim 0.1 \mathrm{~s}^{-1}\right.$ at $40^{\circ} \mathrm{C}$, and $\dot{\gamma} \sim 20 \mathrm{~s}^{-1}$ at $\left.140^{\circ} \mathrm{C}\right)$. This increment can be attributed to thermally-induced changes in particle-particle interactions, as has been pointed out elsewhere (Briscoe et al., 1994). Besides, it is worth mentioning that the influence of pressure on the yield stress values is only significant at the highest temperature studied, resulting in an increase in yield stress with pressure.

Figures 4a-d also show the fitting of both Bingham's and Herschel-Bulkley's models to the experimental flow curves. As can be seen, both models predict the viscous flow behaviour of this oil drilling fluid, at $40^{\circ} \mathrm{C}$ and $140^{\circ} \mathrm{C}$ and in the range of pressure selected, fairly well.

Bingham's and Herschel-Bulkley's parameters are listed, in Tables 1 and 2, for B34-based and B128-based drilling fluids, respectively. In these tables, the values of the Average Absolute Relative Deviation percentage 

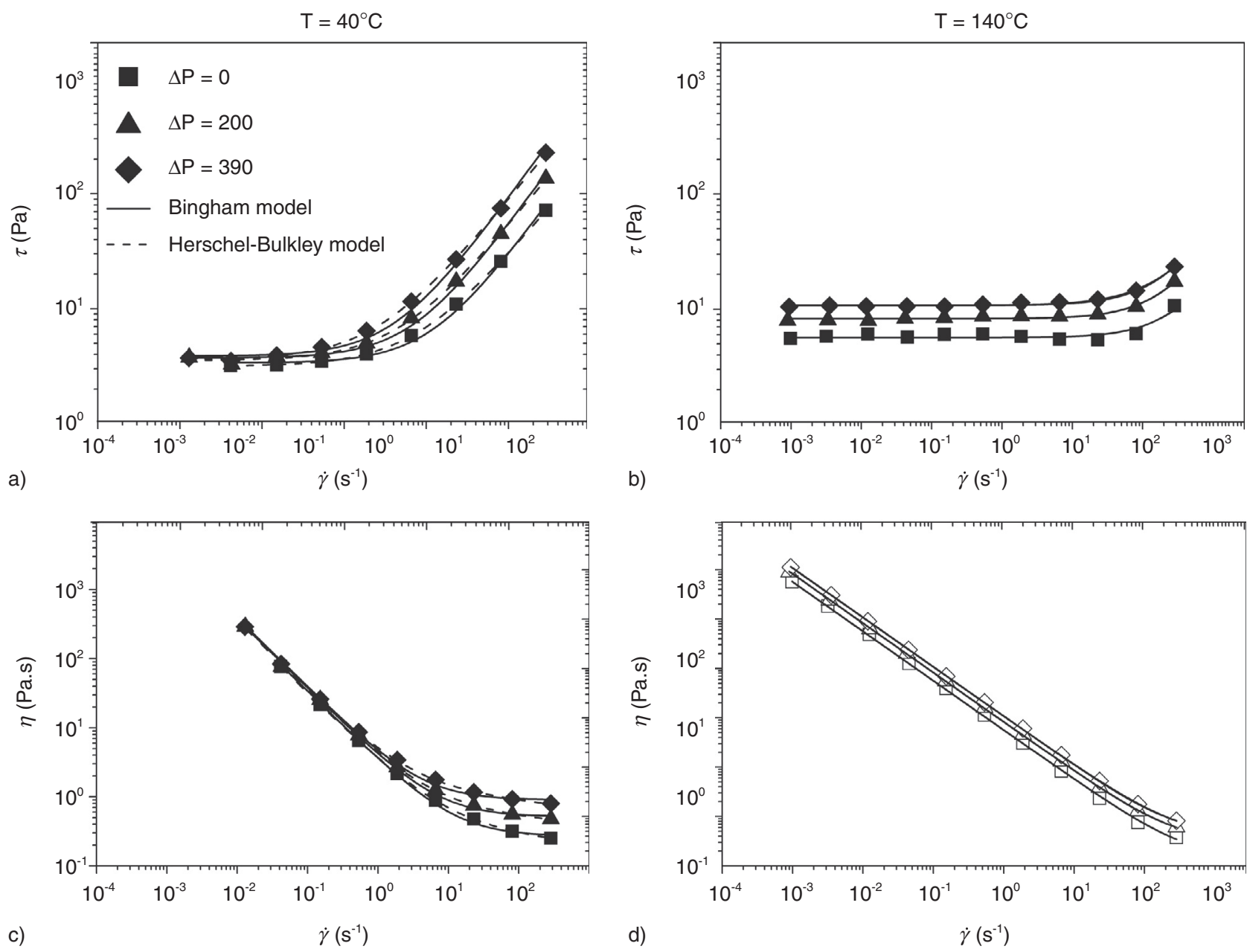

Figure 4

Experimental viscous flow curves a) and b): shear stress versus shear rate: c) and d): viscosity versus shear rate), at three differential pressures $\left(\Delta p=p-p_{0}\right)$ and two temperatures $\left(40\right.$ and $\left.140^{\circ} \mathrm{C}\right)$, and Herschel-Bulkley's and Bingham's models fittings for B128-based drilling fluid.

(\%AARD) have been also included. As shown in Table 1, the values of \%AARD are always lower than $10 \%$, indicating that both models are suitable for describing the viscous flow properties of B34-based oil drilling fluid, in the range of temperature and pressure studied, from an engineering point of view. In Tables 3 and 4 , the correlation coefficients $\left(R^{2}\right)$ and Residual Sum of Squares $(R S S)$ are reported. It is worth noting that Herschel-Bulkley's model always shows significantly lower $R S S$ values and $R^{2}$ values closer to 1 for B34-based drilling fluid. Hence, this model seems to be more reliable to describe the viscous flow behaviour of this drilling fluid. Otherwise, the slight differences in $R S S$ and $R^{2}$ values found with both models, for B128based drilling fluid, would indicate that they are equally valid to model its complex rheological behaviour, under extreme pressure-temperature environments, from an engineering point of view.

\subsubsection{Combined Effect of Pressure and Temperature on Yield Stress}

Figures 5 and 6 display the evolution of the HerschelBulkley yield stress with pressure, in the temperature range comprised between $40^{\circ} \mathrm{C}$ and $140^{\circ} \mathrm{C}$, for $\mathrm{B} 34$ and B128-based drilling fluids, respectively. As can be seen, yield stress always linearly increases with pressure in the range of pressure tested. Consequently, the isothermal yield stress behaviour can be modelled by a simple equation, as follows:

$$
\tau_{c}=\tau_{c 0}+\beta_{\tau}\left(p-p_{0}\right)
$$

where $\tau_{c}$ is the Herschel-Bulkley yield stress, $\tau_{c 0}$ is the yield stress at the reference pressure for each temperature, $\beta_{\tau}$ is a isothermal piezo-yield stress coefficient, $p$ is the applied pressure, and $p_{0}$ is the pressure of reference ( 1 bar). The values of the piezo-yield stress 
TABLE 1

Bingham's and Herschel-Bulkley's parameters and \%AARD for B34-based drilling fluid, at different temperatures and pressures

Bingham's model

\begin{tabular}{c|c|c|c|c|c|c|c|c|c}
\hline$\Delta p$ (bar) & \multicolumn{3}{|c|}{0} & \multicolumn{3}{c}{200} & \multicolumn{3}{c}{390} \\
\hline$T\left({ }^{\circ} \mathrm{C}\right)$ & $\eta_{p}(\mathrm{~Pa} \cdot \mathrm{s})$ & $\tau_{B}(\mathrm{~Pa})$ & $\%$ AARD & $\eta_{p}(\mathrm{~Pa} \cdot \mathrm{s})$ & $\tau_{B}(\mathrm{~Pa})$ & $\%$ AARD & $\eta_{p}(\mathrm{~Pa} \cdot \mathrm{s})$ & $\tau_{B}(\mathrm{~Pa})$ & $\% \mathrm{AARD}$ \\
\hline 40 & 0.164 & 0.16 & 2.9 & 0.301 & 0.41 & 9.5 & 0.502 & 0.74 & 7.3 \\
\hline 80 & 0.030 & 0.07 & 6.3 & 0.043 & 0.11 & 6.3 & 0.063 & 0.20 & 5.2 \\
\hline 100 & 0.017 & 0.08 & 6.7 & 0.023 & 0.11 & 7.3 & 0.028 & 0.17 & 5.6 \\
\hline 120 & 0.012 & 0.01 & 6.4 & 0.014 & 0.12 & 4.5 & 0.020 & 0.15 & 1.9 \\
\hline 140 & 0.009 & 0.14 & 5.6 & 0.017 & 0.18 & 5.9 & 0.019 & 0.21 & 4.9 \\
\hline
\end{tabular}

Herschel-Bulkley's model

\begin{tabular}{c|c|c|c|c|c|c|c|c|c|c|c|c}
\hline$\Delta p$ (bar) & \multicolumn{4}{|c|}{0} & \multicolumn{3}{c|}{200} & \multicolumn{3}{c}{390} \\
\hline$T\left({ }^{\circ} \mathrm{C}\right)$ & $K\left(\mathrm{~Pa} \cdot \mathrm{s}^{-n}\right)$ & $n$ & $\tau_{H}(\mathrm{~Pa})$ & $\%$ AARD & $K\left(\mathrm{~Pa} \cdot \mathrm{s}^{-n}\right)$ & $n$ & $\tau_{H}(\mathrm{~Pa})$ & $\% \mathrm{AARD}$ & $\mathrm{K}\left(\mathrm{Pa} \cdot \mathrm{s}^{-n}\right)$ & $n$ & $\tau_{H}(\mathrm{~Pa})$ & $\% \mathrm{AARD}$ \\
\hline 40 & 0.188 & 0.97 & 0.12 & 0.4 & 0.436 & 0.92 & 0.27 & 3.3 & 0.668 & 0.94 & 0.56 & 2.6 \\
\hline 80 & 0.044 & 0.89 & 0.06 & 1.6 & 0.064 & 0.89 & 0.09 & 1.8 & 0.091 & 0.90 & 0.17 & 0.8 \\
\hline 100 & 0.033 & 0.84 & 0.05 & 1.8 & 0.038 & 0.85 & 0.08 & 3.1 & 0.042 & 0.88 & 0.14 & 1.8 \\
\hline 120 & 0.025 & 0.82 & 0.08 & 2.0 & 0.023 & 0.87 & 0.10 & 1.2 & 0.022 & 0.95 & 0.15 & 0.8 \\
\hline 140 & 0.038 & 0.69 & 0.12 & 0.1 & 0.048 & 0.67 & 0.15 & 1.1 & 0.050 & 0.71 & 0.18 & 0.2 \\
\hline
\end{tabular}

$\%$ AARD $=1 / N\left(\Sigma\left|\left(\tau_{\text {cal }}-\tau_{\exp }\right) / \tau_{\text {exp }}\right|\right) \times 100$

TABLE 2

Bingham's and Herschel-Bulkley's parameters and \%AARD for B128-based drilling fluid, at different temperatures and pressures

\begin{tabular}{|c|c|c|c|c|c|c|c|c|c|c|c|c|}
\hline \multicolumn{13}{|c|}{ Bingham's model } \\
\hline \multirow{2}{*}{$\frac{\Delta p \text { (bar) }}{T\left({ }^{\circ} \mathrm{C}\right)}$} & \multicolumn{4}{|c|}{0} & \multicolumn{4}{|c|}{200} & \multicolumn{4}{|c|}{390} \\
\hline & \multicolumn{2}{|c|}{$\eta_{p}(\mathrm{~Pa} \cdot \mathrm{s})$} & $\tau_{B}(\mathrm{~Pa})$ & $\%$ AARD & \multicolumn{2}{|c|}{$\eta_{p}(\mathrm{~Pa} \cdot \mathrm{s})$} & $\tau_{B}(\mathrm{~Pa})$ & $\%$ AARD & \multicolumn{2}{|l|}{$\eta_{p}(\mathrm{~Pa} \cdot \mathrm{s})$} & $\tau_{B}(\mathrm{~Pa})$ & $\%$ AARD \\
\hline 40 & \multicolumn{2}{|c|}{0.270} & 3.38 & 3.8 & \multicolumn{2}{|l|}{0.517} & 3.74 & 6.8 & \multicolumn{2}{|l|}{0.899} & 3.87 & 8.5 \\
\hline 80 & \multicolumn{2}{|c|}{0.065} & 2.72 & 4.2 & \multicolumn{2}{|l|}{0.092} & 3.01 & 3.0 & \multicolumn{2}{|l|}{0.132} & 3.60 & 3.5 \\
\hline 100 & \multicolumn{2}{|c|}{0.034} & 3.02 & 4.3 & \multicolumn{2}{|l|}{0.049} & 3.39 & 3.7 & \multicolumn{2}{|l|}{0.066} & 4.04 & 5.2 \\
\hline 120 & \multicolumn{2}{|c|}{0.020} & 3.48 & 4.7 & \multicolumn{2}{|l|}{0.029} & 4.81 & 5.0 & \multicolumn{2}{|l|}{0.042} & 5.86 & 3.4 \\
\hline 140 & \multicolumn{2}{|c|}{0.015} & 5.64 & 5.6 & \multicolumn{2}{|l|}{0.031} & 8.26 & 2.5 & \multicolumn{2}{|l|}{0.045} & 10.81 & 2.1 \\
\hline \multicolumn{13}{|c|}{ Herschel-Bulkley's model } \\
\hline$\Delta p$ (bar) & \multicolumn{4}{|c|}{0} & \multicolumn{4}{|c|}{200} & \multicolumn{4}{|c|}{390} \\
\hline$T\left({ }^{\circ} \mathrm{C}\right)$ & $K\left(\mathrm{~Pa} \cdot \mathrm{s}^{-n}\right)$ & $n$ & $\tau_{H}(\mathrm{~Pa})$ & $\%$ AARD & $K\left(\mathrm{~Pa} \cdot \mathrm{s}^{-n}\right)$ & $n$ & $\tau_{H}(\mathrm{~Pa})$ & $\%$ AARD & $K\left(\mathrm{~Pa} \cdot \mathrm{s}^{-n}\right)$ & $n$ & $\tau_{H}(\mathrm{~Pa})$ & $\%$ AARD \\
\hline 40 & 0.519 & 0.86 & 3.16 & 0.3 & 0.854 & 0.89 & 3.55 & 3.3 & 1.508 & 0.88 & 3.62 & 2.3 \\
\hline 80 & 0.068 & 0.99 & 2.71 & 4.7 & 0.096 & 0.99 & 3.01 & 3.1 & 0.137 & 0.99 & 3.59 & 3.5 \\
\hline 100 & 0.036 & 0.99 & 3.05 & 4.5 & 0.053 & 0.98 & 3.39 & 4.3 & 0.069 & 0.99 & 4.04 & 5.6 \\
\hline 120 & 0.022 & 0.98 & 3.47 & 4.7 & 0.032 & 0.98 & 4.80 & 5.4 & 0.043 & 0.99 & 5.86 & 3.3 \\
\hline 140 & 0.016 & 0.99 & 5.64 & 5.6 & 0.034 & 0.98 & 8.25 & 2.5 & 0.081 & 0.89 & 10.74 & 1.9 \\
\hline
\end{tabular}


TABLE 3

Correlation coefficient $\left(R^{2}\right)$ and Residual Sum of Squares $(R S S)$ of models used for B34-based drilling fluid, at different temperatures and pressures

\begin{tabular}{|c|c|c|c|c|c|c|}
\hline \multicolumn{7}{|c|}{ Bingham's Model } \\
\hline$\Delta p$ (bar) & \multicolumn{2}{|c|}{0} & \multicolumn{2}{|c|}{200} & \multicolumn{2}{|c|}{390} \\
\hline$T\left({ }^{\circ} \mathrm{C}\right)$ & $R^{2}$ & $R S S\left(\mathrm{~Pa}^{2}\right)$ & $R^{2}$ & $R S S\left(\mathrm{~Pa}^{2}\right)$ & $R^{2}$ & $R S S\left(\mathrm{~Pa}^{2}\right)$ \\
\hline 40 & 0.9992 & 0.0066 & 0.9919 & 0.0857 & 0.9951 & 0.0511 \\
\hline 80 & 0.9945 & 0.0243 & 0.9944 & 0.0244 & 0.9958 & 0.0167 \\
\hline 100 & 0.9933 & 0.0209 & 0.9904 & 0.0276 & 0.9933 & 0.0178 \\
\hline 120 & 0.9927 & 0.0180 & 0.9963 & 0.0086 & 0.9993 & 0.0016 \\
\hline 140 & 0.9864 & 0.0138 & 0.9851 & 0.0146 & 0.9889 & 0.0109 \\
\hline \multicolumn{7}{|c|}{ Herschel-Bulkley's Model } \\
\hline$\Delta p$ (bar) & \multicolumn{2}{|c|}{0} & \multicolumn{2}{|c|}{200} & \multicolumn{2}{|c|}{390} \\
\hline$T\left({ }^{\circ} \mathrm{C}\right)$ & $R^{2}$ & $R S S\left(\mathrm{~Pa}^{2}\right)$ & $R^{2}$ & $R S S\left(\mathrm{~Pa}^{2}\right)$ & $R^{2}$ & $R S S\left(\mathrm{~Pa}^{2}\right)$ \\
\hline 40 & 0.9999 & $1.5 \mathrm{E}-4$ & 0.9985 & 0.0112 & 0.9994 & 0.0065 \\
\hline 80 & 0.9996 & 0.0017 & 0.9995 & 0.0020 & 0.9999 & 4.5E-4 \\
\hline 100 & 0.9995 & 0.0016 & 0.9984 & 0.0047 & 0.9994 & 0.0016 \\
\hline 120 & 0.9992 & 0.0020 & 0.9997 & 0.0007 & 0.9999 & 0.0003 \\
\hline 140 & 0.9999 & $4 \mathrm{E}-7$ & 0.9994 & 0.0006 & 0.9999 & $1.4 \mathrm{E}-5$ \\
\hline
\end{tabular}

$R S S=\Sigma\left|\left(\tau_{\mathrm{cal}}-\tau_{\mathrm{exp}}\right)^{2}\right|$

coefficient in a temperature range comprised between $40^{\circ} \mathrm{C}$ and $140^{\circ} \mathrm{C}$, for both oil drilling fluids, are shown in Table 5. As can be observed in these figures, the influence of pressure on the yield stress is more significant for B128-based drilling fluid, which also shows the highest values of yield stress. Similar behaviour, in the low shear-rate region, has been reported by Gandelman et al. (2007).

Changes in B34-based drilling fluid piezo-yield stress could be associated with the thermal weakening of interparticle interactions in the agglomerates and reduction in the effective agglomerate concentration, being the yielding behaviour less sensitive to pressure changes as temperature increases, even enhancing its compressibility with temperature (Paredes et al., 2012). In addition, this decrease in yield stress with an increase in temperature may be related to a decrease in oil viscosity (Houwen and Geehan, 1986).

On the contrary, for B128-based drilling fluid, the pressure/temperature dependence of the yield stress is quite different. As can be seen in Figure 6, yield stress dependence on pressure is roughly independent of temperature below $120^{\circ} \mathrm{C}$. In addition, the larger influence of pressure on this parameter could be related to the compression of a thermally-modified denser structure, as have been pointed out by Politte (1985) for inverted oil muds.

From the engineering point of view, the temperature and pressure dependence of the yield stress is of major interest for the design of transport operations in the oil drilling industry (Darley and Gray, 1988). In this sense, drilling fluids are mainly designed to be able of suspending drill cuttings under static conditions. According to the results obtained in this study, the B34-based oil drilling fluid presents fairly low cutting carrying capacity, but also not excessive horse-power pump requirements in the range of pressure and temperature tested (see yield stress values in Tab. 1). On the contrary, B128 organoclay can be considered a potential candidate to prepare suspensions able to be used for drilling fluid applications, with yield stress values below $15 \mathrm{~Pa}$ (Munawar and Jan, 2012a) in the whole range of pressure and temperatures studied.

\subsubsection{Temperature-Pressure-Plastic Viscosity Relationship}

The combined effect of temperature and pressure on the viscous flow properties of many materials has been 
TABLE 4

Correlation coefficient $\left(R^{2}\right)$ and Residual Sum of Squares $(R S S)$ of models used for B128-based drilling fluid, at different temperatures and pressures

\begin{tabular}{c|c|c|c|c|c|c}
\hline \multicolumn{2}{|c|}{ Bingham's Model } & \multicolumn{2}{c}{200} & \multicolumn{2}{c}{390} \\
\hline$\Delta p($ bar $)$ & \multicolumn{2}{|c|}{0} & $R S S\left(\mathrm{~Pa}^{2}\right)$ & $R^{2}$ & $R S S\left(\mathrm{~Pa}^{2}\right)$ & $R^{2}$ \\
\hline$T\left({ }^{\circ} \mathrm{C}\right)$ & $R^{2}$ & 0.0520 & 0.9756 & 0.0662 & 0.9726 & 0.0860 \\
\hline 40 & 0.9769 & 0.0299 & 0.9784 & 0.0140 & 0.9960 & 0.0029 \\
\hline 80 & 0.9340 & 0.0305 & 0.9364 & 0.0206 & 0.9152 & 0.0310 \\
\hline 100 & 0.8878 & 0.0391 & 0.9380 & 0.0289 & 0.9674 & 0.0184 \\
\hline 120 & 0.9199 & 0.0469 & 0.9700 & 0.0092 & 0.9811 & 0.0065 \\
\hline
\end{tabular}

Herschel-Bulkley's Model

\begin{tabular}{c|c|c|c|c|c|c}
\hline$\Delta p$ (bar) & \multicolumn{2}{|c|}{0} & \multicolumn{2}{c}{200} & \multicolumn{2}{c}{390} \\
\hline$T\left({ }^{\circ} \mathrm{C}\right)$ & $R^{2}$ & $R S S\left(\mathrm{~Pa}^{2}\right)$ & $R^{2}$ & $R S S\left(\mathrm{~Pa}^{2}\right)$ & $R^{2}$ & $R S S\left(\mathrm{~Pa}^{2}\right)$ \\
\hline 40 & 0.9998 & 0.0005 & 0.9939 & 0.0165 & 0.9978 & 0.0069 \\
\hline 80 & 0.9418 & 0.0308 & 0.9783 & 0.0141 & 0.9963 & 0.0027 \\
\hline 100 & 0.8833 & 0.0317 & 0.9329 & 0.0218 & 0.9133 & 0.9668 \\
\hline 120 & 0.9187 & 0.0397 & 0.9335 & 0.0310 & 0.0187 \\
\hline 140 & 0.7855 & 0.0479 & 0.9697 & 0.0094 & 0.9846 & 0.0053 \\
\hline
\end{tabular}

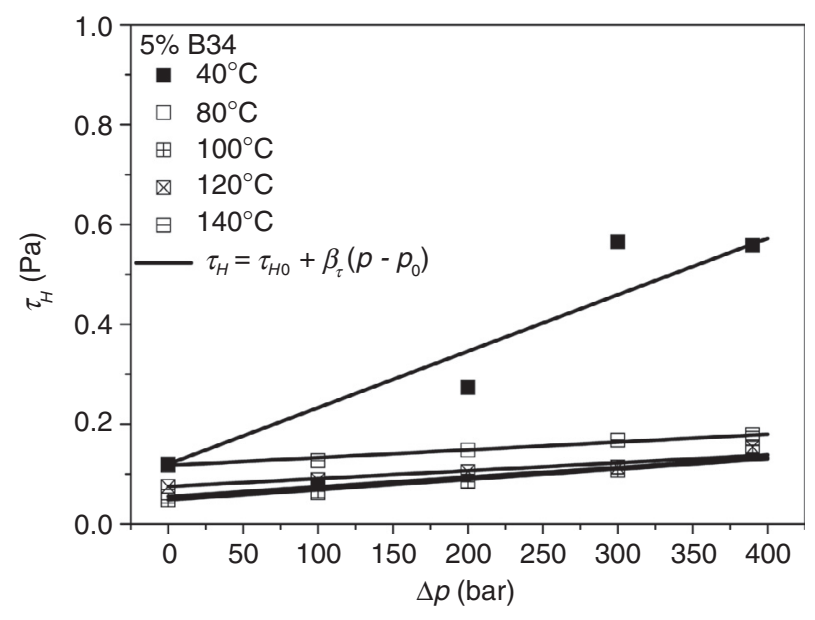

Figure 5

Effect of pressure on Herschel-Bulkley's yield stress for B34-based drilling fluid, as a function of temperature.

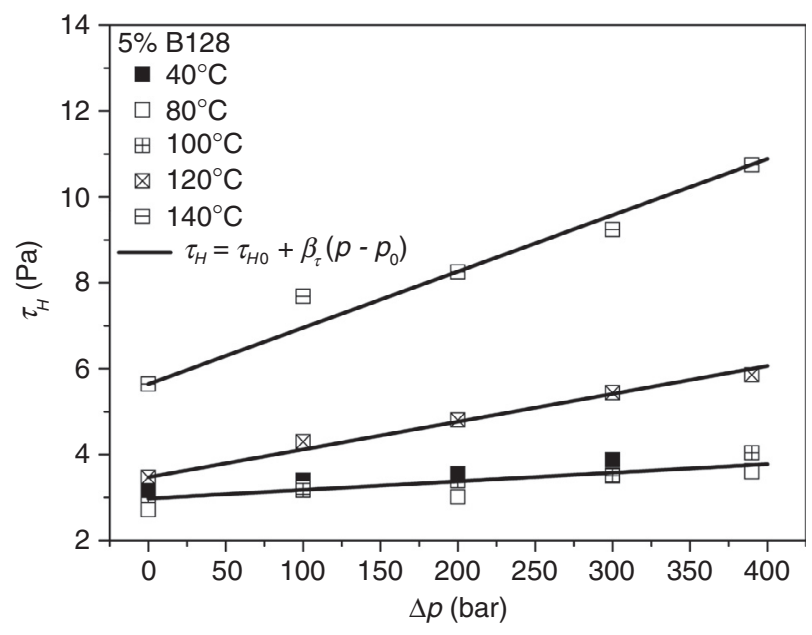

Figure 6

Effect of pressure on Herschel-Bulkley's yield stress for B128-based drilling fluid, as a function of temperature. described by using a large variety of models, such as models based on physical properties, empirical equations or factorial equations of temperature and pressure
(Tschoegl et al., 2002; Bair, 2007; Rajagopal and Saccomandi, 2009; Fuentes-Audén et al., 2005; Fan and Wang, 2011). 
TABLE 5

Piezo-yield stress coefficients for the oil drilling fluids studied, at different temperatures

\begin{tabular}{c|c|c|c|c}
\hline \multirow{2}{*}{} & \multicolumn{2}{|c|}{ B34 } & \multicolumn{2}{c}{ B128 $\beta_{\tau}\left(\times 10^{4}, \mathrm{~Pa} / \mathrm{bar}\right)$} \\
\cline { 2 - 5 } & \multicolumn{2}{|c|}{$\beta_{\tau}\left(\times 10^{4}, \mathrm{~Pa} / \mathrm{bar}\right)$} & Bingham's model & Herschel-Bulkley's model \\
\hline$T\left({ }^{\circ} \mathrm{C}\right)$ & Bingham's model & Herschel-Bulkley's model & 16.5 & 16.8 \\
\hline 40 & 15.6 & 11.3 & 23.9 & 23.6 \\
\hline 80 & 2.36 & 1.94 & 20.8 & 19.6 \\
\hline 100 & 2.04 & 2.06 & 64.9 & 64.8 \\
\hline 140 & 1.25 & 1.59 & 132 & 131 \\
\hline
\end{tabular}

In this case, a factorial WLF-Barus equation has been selected:

$$
\eta(p, T)=\eta_{0} 10^{\left(-\frac{c_{1}\left(T-T_{0}\right)}{c_{2}+\left(T-T_{0}\right)}\right)} \exp \left(\beta(T)\left(p-p_{0}\right)\right)
$$

being:

$$
\beta(T)=\beta_{0}+\beta_{1}\left(T-T_{0}\right)
$$

where $\eta_{0}$ is the plastic viscosity of the fluid at atmospheric pressure, $p_{0}$, and temperature of reference, $T_{0} ; c_{1}$ and $c_{2}$ are empirical constants; and $\beta(T)$ is the piezo-viscous coefficient, which has been linearized with temperature to generalize the model using two parameters, $\beta_{0}$ and $\beta_{1}$.

Figure 7 shows the experimental plastic viscosity values as a function of pressure, and the fitting of WLF-Barus' model, for B34 and B128-based drilling fluids, in a temperature range comprised between 40 and $140^{\circ} \mathrm{C}$. In addition, the Newtonian viscosities, at 40 and $140^{\circ} \mathrm{C}$, of SR-10 base oil have been included for the sake of comparison. As can be seen in these figures, the factorial WLF-Barus model fits the pressure (in the range of 1-390 bar) and temperature (between 40 and $140^{\circ} \mathrm{C}$ ) dependence of plastic viscosity, for both drilling fluids, fairly well. Nevertheless, it must be mentioned that, in both cases, the fitting shows a slightly higher deviation at $140^{\circ} \mathrm{C}$. WLF-Barus' parameters are listed in Table 6 . At $40^{\circ} \mathrm{C}$, the evolution of drilling fluid viscosity with pressure is quite similar to that found for the base oil (Hermoso et al., 2014). Likewise, the decrease observed in the piezo-viscous coefficient with temperature is progressively less marked as temperature increases (Tab. 6), as reported elsewhere (Chaudemanche et al., 2009) Hence, the influence of pressure is mainly dependent on base oil flow properties,
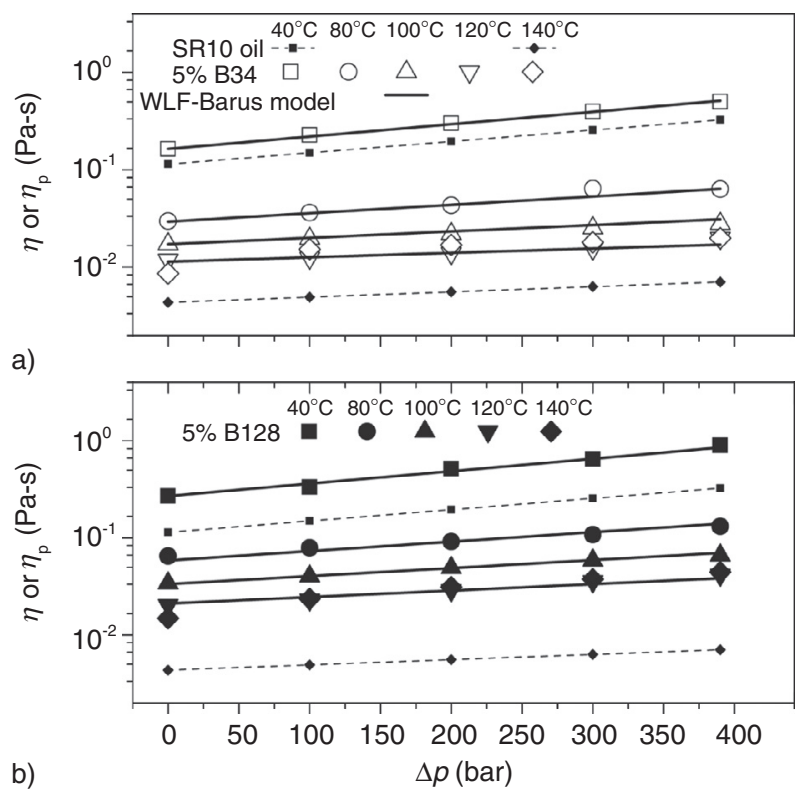

Figure 7

Experimental viscosities (SR-10 oil) and plastic viscosities (drilling fluids) as a function of pressure, and WLF-Barus' model fitting, in a temperature range of $40-140^{\circ} \mathrm{C}$. a) B34-based drilling fluid; and b) B128-based drilling fluid.

as has been pointed out by different authors (Houwen and Geehan, 1986; Hermoso et al., 2014). It also interesting to notice that B34-based drilling fluid piezo-viscous coefficient presents a slightly higher temperature dependence than both B128-based one and SR10 oil, as can be seen in Table 6. In addition, B34-based drilling fluid exhibits lower viscosity values than B128-based one in the whole range of temperature and pressure tested. The slight differences between both drilling fluids at high shear rates should be related to changes in organoclay suspension microstructure as temperature increases. 
TABLE 6

WLF-Barus' model parameters for the base oil and drilling fluids studied

\begin{tabular}{l|c|c|c|c|c}
\hline Sample & $\eta_{0}(\mathrm{~Pa} \cdot \mathrm{s})$ & $c_{1}$ & $c_{2}\left({ }^{\circ} \mathrm{C}\right)$ & $\beta_{0}(1 / \mathrm{bar})$ & $\beta_{1}\left(1 / \mathrm{bar} \cdot{ }^{\circ} \mathrm{C}\right)$ \\
\hline SR-10 oil & 0.114 & 2.54 & 80.65 & $2.62 \times 10^{-3}$ & $-1.43 \times 10^{-5}$ \\
\hline B34-based fluid & 0.164 & 2.58 & 98.03 & $2.92 \times 10^{-3}$ & $-2.34 \times 10^{-5}$ \\
\hline B128-based fluid & 0.270 & 3.31 & 159.08 & $2.95 \times 10^{-3}$ & $-1.76 \times 10^{-5}$ \\
\hline
\end{tabular}

\subsubsection{Influence of Pressure and Temperature on Herschel- Buckley's Flow Index}

The effect of temperature and pressure on the HerschelBuckley flow index of the oil drilling fluids studied can be analysed from the data shown in Tables 1 and 2. As can be seen, the flow indexes are always lower than 1 for the suspension formulated with B34 organoclay, showing a moderate shear-thinning behaviour (Park and Song, 2010). In addition, the influence of pressure on this parameter is not significant between 1 and 390 bar. It is important to remark that the flow index slightly decreases as temperature increases up to $120^{\circ} \mathrm{C}$ and then suddenly drops at $140^{\circ} \mathrm{C}$.

On the other hand, changes in B128-based oil drilling fluid flow index with both pressure and temperature are very weak. In this sense, at $40^{\circ} \mathrm{C}$, this fluid shows very similar flow index values, slightly shear-thinning, in the whole pressure range tested. At temperatures above $40^{\circ} \mathrm{C}$, the flow index is independent of both temperature and pressure (Tab. 2).

\section{CONCLUSIONS}

In this study, HPHT viscous flow characterization of oil drilling fluids formulated with two different organoclays was performed by using a non-conventional geometry coupled to a rheometer. The experimental results indicate that the double helical ribbon geometry is a very useful tool to characterise the complex viscous flow behaviour of these fluids under high pressure.

From the experimental results obtained at atmospheric pressure, it can be concluded that the viscous flow behaviour of these drilling fluids is strongly affected by both the organically modified surface-oil pair solvency and oil viscosity, in the temperature range studied. The low yield stress values for B34-based drilling fluid suggest a short-range attractive force between the particles, which develop a network of aggregates weakly interconnected. On the other hand, the increase in yield stress for B128-based drilling fluid, above a threshold temperature, may be associated with structural changes due to thermal gelling.
Both Bingham's and Herschel-Bulkley's models fitted the complex viscous flow behaviour of these drilling fluids, at different pressures and temperatures, fairly well. However, Herschel-Bulkley's model is statistically better to account for changes in the viscous behaviour of B34-based drilling fluids under HPHT conditions. Drilling fluids yield stresses increase with pressure, whilst their temperature dependence is related to the type of organoclay used. This behaviour may be explained on the basis of oil compression and thermally-induced changes in the effective organoclay volume fraction. A factorial WLF-Barus model satisfactorily describes the temperature/pressure evolution of the plastic viscosity for both drilling fluids, being the viscosity at high shear rate mainly influenced by the piezo-viscous properties of the continuous phase.

\section{ACKNOWLEDGMENTS}

This work has been sponsored by the "Junta de Andalucía" FEDER-Excellence Projects Programme (Research project P08-TEP-3895). The authors gratefully acknowledge its financial support.

\section{REFERENCES}

Abu-Jdayil B. (2011) Rheology of sodium and calcium bentonitewater dispersions: Effect of electrolytes and aging time, Int. J. Miner. Process. 98, 208-213.

Bair S. (2007) High Pressure Rheology for Quantitative Elastohydrodynamics, first edition, Elsevier BV, Oxford, UK.

Barnes H.A., Nguyen Q.D. (2001) Rotating vane rheometry - a review, J. Non-Newtonian Fluid Mech. 98, 1-14.

Briscoe B.J., Luckham P.F., Ren S.R. (1994) The properties of drilling fluids at high pressures and high temperatures, Philos. T. Roy. Soc. A 348, 179-207.

Burgentzlé D., Duchet J., Gérard J.F., Jupin A., Fillon B. (2004) Solvent-based nanocomposite coatings I. Dispersions of organophilic montmorillonite in organic solvents, J. Colloid Interf. Sci. 278, 26-39.

Caenn R., Chillingar G.V. (1996) Drillings Fluids: State of art, J. Pet. Sci. Eng. 14, 221-230.

Chaudemanche C., Henaut I., Argillier J.-F. (2009) Combined Effect of Pressure and Temperature on Rheological Properties Water-in-Crude Oil Emulsions, Appl. Rheol. 19, 1-8. 
Darley H.C.H., Gray G.R. (1988) Composition and Properties of Drilling Fluids and Completion Fluids, Gulf Professional Publishing, Houston, Texas.

Fan Y., Wang K. (2011) The Viscosity of Dimethyl Silicone Oil and the Concentration of Adsorbed Air, AiChE J. 57, 3299-3304.

Fuentes-Audén C., Martínez-Boza F., Navarro F.J., Partal P., Gallegos C. (2005) Viscous flow properties and phase behavior of oil-resin blends, Fluid Phase Equilib. 237, 117-122.

Gandelman R.A., Leal R.A.F., Gonçalves J.T., Aragão A.F. L., Lomba R.F., Martins A.L. (2007) Study on Gelation and Freezing Phenomena of Synthetic Drilling Fluids in Ultra Deep Water Environments, SPE/IADC Drilling Conference, Amsterdam, Netherlands, 20-22 Feb.

Ghalambor A., Ashrafizadeh S.N., Nasiri M. (2008) Effect of basic parameters on the viscosity of synthetic-based drilling fluids, SPE International Symposium on Formation Damage Control, Lafayette, Louisiana, 13-15 Feb.

Harris O.O., Osisanya S.O. (2005) Evaluation of equivalent circulating density of drilling fluids under high pressure/high temperature conditions, SPE Annual Technical and Exhibition Conference, Dallas, Texas, 9-12 Oct.

Hermoso J., Jofore B.D., Martínez-Boza F.J., Gallegos C. (2012) High Pressure Mixing Rheology of Drilling Fluids, Ind. Eng. Chem. Res. 51, 14399-14407.

Hermoso J., Martínez-Boza F.J., Gallegos C. (2014) Influence of Viscosity Modifier Nature and Concentration on the Viscous Flow Behavior of Oil-based Drilling Fluid, Appl. Clay Sci. 87, 14-21.

Herzhaft B., Peysson Y., Isambourg P., Delepoulle A., Toure A. (2001) Rheological Properties of Drilling Muds in Deep Offshore Conditions, SPE/IADC Drilling Conference, Amsterdam, Netherlands, 27 Feb.-1 March.

Herzhaft B., Rousseau L., Neau L., Moan M., Bossard F. (2003) Influence of temperature and clay/emulsion microstructure on oil-based mud low shear rate rheology, SPE J. 8, 211-217.

Houwen O.H., Geehan T. (1986) Rheology of Oil-Base Muds, SPE Annual Technical Conference and Exhibition, New Orleans, Louisiana, 5-8 Oct.

Joshi R.M., Pegg M.J. (2007) Flow properties of biodiesel fuel blends at low temperatures, Fuel 86, 143-151.

Kelessidis V.C., Christidis G., Makri P., Hadjistamou V., Tsamantaki C., Mihalakis A., Papanicolaou C., Foscolos A. (2007) Gelation of water-bentonite suspensions at high temperature and rheological control with lignite addition, Appl. Clay Sci. 36, 221-231.

Kelessidis V.C., Papanicolaou C., Foscolos A. (2009) Application of Greek lignite as an additive for controlling rheological and filtration properties of water-bentonite suspensions at high temperatures: A review, Int. J. Coal Geol. 77, 394-400.

Lu G., Li X., Chen T., Shan J., Gao Y. (2008) New method for non-linear least square estimation on rheological parameter in Casson model of drilling fluid, Shiyou Xuebao/Acta Petrolei Sinica 29, 470-474.

Massinga P.H., Focke W.W., de Vaal P.L., Atanasova M. (2010) Alkyl ammonium intercalation of Mozambican bentonite, Appl. Clay Sci. 49, 142-148.

Minase M., Kondo M., Onikata M., Kawamura K. (2008) The viscosity of organic liquid suspensions of trimethyldococylammonium-montmorillonite complexes, Clays Clay Miner. 56, 49-65.
Møller P.C.F., Mewis J., Bonn D. (2006) Yield stress and thixotropy: On the difficulty of measuring yield stress in practice, Soft Matter 2, 274-283.

Moraru V.N. (2001) Structure formation of alkylammonium montmorillonites in organic media, Appl. Clay Sci. 19, 11-26.

Munawar K., Jan B.M. (2012a) Herschel-Bulkley rheological parameters of a novel environmentally friendly lightweight biopolymer drilling fluid xanthan gum and starch, J. Appl. Polym. Sci. 124, 595-606.

Munawar K., Jan B.M. (2012b) Viscoplastic modeling of a novel lightweight biopolymer drilling fluid for unbalanced drilling, Ind. Eng. Chem. Res. 51, 4056-4068.

O'Shea J.-P., Tallon C. (2011) Yield stress behavior of concentrated silica suspensions with temperature-responsive polymers, Colloids Surf. A 385, 40-46.

Paredes X., Fandiño O., Pensado A.S., Comuñas M.J.P., Fernández J. (2012) Pressure-Viscosity Coefficients for Polyalkylene Glycol Oils and Other Ester Ionic Lubricants, Tribol. Lett. 45, 89-100.

Park E.-K., Song K.-W. (2010) Rheological Evaluation of Petroleum Jelly as a Base Material in Ointment and Cream Formulations: Steady Shear Flow Behavior, Arch. Pharm. Res. 33, 141-150.

Politte M.D. (1985) Invert Oil Mud Rheology as a Function of Temperature and Pressure, SPE/IADC Drilling Conference, New Orleans, Louisiana, 5-8 March.

Quemada D., Berli C. (2002) Energy of interaction in colloids and its implications in rheological modeling, Adv. Colloid Interface Sci. 98, 51-58.

Rajagopal K.R., Saccomandi G. (2009) The mechanics and mathematics of the effect of pressure on the shear modulus of elastomers, P. Roy. Soc. Lond. A Mat. 465, 3859-3874.

Rossi S., Luckham P.F., Zhu S., Briscoe B.J. (1999) HighPressure/High-Temperature Rheology of $\mathrm{Na}^{+}$-Montmorillonite Clay Suspensions, Proceedings of the 1999 SPE International Symposium on Oilfield Chemistry, Houston, Texas, 16-19 Feb.

Rossi S., Luckham P.F., Tadros ThF (2002) Influence of nonionic polymers on the rheological behavior of $\mathrm{Na}+$-montmorillonite clay suspensions-I Nonyphenol-polypropylene oxide -polyethylene oxide copolymers, Colloids Surf. A 201, 85-100.

Shahbazi K., Metha S.A., Moore R.G., Ursenbanch M.G., Fraassen K.C.V. (2007) Oxidation as a Rheology Modifier and a Potential Cause of Explosions in Oil and Synthetic-Based Drilling Fluids, International Symposium on Oilfield Chemistry, Houston, Texas, 28 Feb.-2 March.

Tropea C., Yarin A.L., Foss J.F. (2007) Springer Handbook of Experimental Fluid Mechanics, Springer Verlag, Berlin, Heidelberg, pp. 705.

Tschoegl N.W., Knauss W.G., Emri I. (2002) The Effect of Temperature and Pressure on the Mechanical Properties of Thermo-and/or Piezorheologically Simple Polymeric Materials in Thermodynamic Equilibrium - A Critical Review, Mech. Time-Depend. Mater. 6, 53-99.

Williams H., Khatri D., Vaughan M., Landry G., Janner L., Mutize B., Herrera M. (2011) Particle Size DistributionEngineered Cementing Approach Reduces Need for Polymeric Extenders in Haynesville Shale Horizontal Reach Wells, SPE Annual Technical and Exhibition Conference, Denver, Colorado, 30 Oct.-2 Nov. 
Wu X.-J., Wang Y., Wang M., Yang W., Xie B.-H., Yang M.-B. (2012) Structure of fumed silica gels in dodecane: Enhanced network by oscillatory shear, Colloid Polym. Sci. 290, 151-161.

Zhao S., Yan J., Shu Y., Li H., Li L., Ding T. (2009) Prediction model for rheological parameters of oil-based drilling fluids at high temperature and high pressure, Shiyou Xuebao/Acta Petrolei Sinica 30, 603-606.
Manuscript accepted in January 2014 Published online in May 2014 made or distributed for profit or commercial advantage and that copies bear this notice and the full citation on the first page. Copyrights for components of this work owned by others than IFP Energies nouvelles must be honored. Abstracting with credit is permitted. To copy otherwise, to republish, to post on servers, or to redistribute to lists, requires prior specific permission and/or a fee: request permission from Information Mission, IFP Energies nouvelles, revueogst@ifpen.fr. 